\title{
A NOÇÃO DE "EMPRESARIADO" SEGUNDO O PONTO DE VISTA DOS “CLÁSSICOS” NORTE- AMERICANOS E OS ESTUDOS PIONEIROS NO BRASIL
}

\author{
THE CONCEPT OF "ENTREPRENEURSHIP" ACCORDING to THE POINT OF VIEW OF THE "CLASSICS" AMERICANS AND thE \\ PIONEERING STUDIES IN BRAZIL
}

\author{
Fernando Lemes* \\ fernando.lemes@ueg.br \\ Dulce Portilho* \\ dportilho@uol.com.br
}

RESUMO: O objetivo do artigo é promover uma aproximação adequada ao exame dos processos de produção e reprodução do capital nas condições do desenvolvimento histórico brasileiro recente, tomando como referência a personificação do capital na pessoa do empresário. Ao lado de uma discussão a respeito dos mecanismos implicados nos processos de acumulação de capital, dedicamos especial atenção à decifração deste personagem, mediante ideias desenvolvidas por autores clássicos da vertente norte-americana e estudos pioneiros realizados no Brasil. Sem perder de vista a referência de certos paradigmas teórico-metodológicos, buscou-se apreender modelos e categorias mais diretamente relacionados com a função dinâmica das unidades de produção sob a ótica de seu vínculo com o empresário.

PALAVRAS-CHAVE: História das Empresas, História Econômica, Empresário, Empresariado.

ABSTRACT: The purpose of the article is to promote an adequate theoretical approach to the examination of the processes of production and reproduction of capital under the conditions of Brazilian recent history development, taking as a reference the personification of capital in the person of the entrepreneur. Next to a discussion about the mechanisms involved in the processes of capital accumulation, we dedicate special attention to the decipherment of the character named Manager, upon ideas developed by classical authors and pioneers. Without losing sight of the reference of certain theoretical and methodological paradigms to grasp models and categories most directly related to the dynamic role of the production units under the optics of your bond with the Manager.

KEYWORDS: History of Companies, Economic History, Businessman, Business community.

\section{Introdução}

A compreensão do processo de desenvolvimento de uma sociedade exige o estudo do sistema econômico nela vigente e seu funcionamento. Estes, por sua vez, somente podem ser compreendidos satisfatoriamente partindo-se do estudo das unidades típicas que realizam a exploração econômica. Nas condições da história contemporânea tais unidades são representadas pelas empresas, ou seja, as unidades produtoras industriais, comerciais, agrárias e de serviços.

\footnotetext{
* Doutor em História pela Universidade Sorbonne Nouvelle - Paris III, professor no Programa de Pós-Graduação stricto sensu em Territórios e Expressões Culturais no Cerrado (TECCER) da Universidade Estadual de Goiás (UEG) e coordenador do Núcleo de Pesquisa Científica (NPC) da Faculdade de Direito Raízes.

* Doutora em História pela Universidade Federal Fluminense (UFF) e professora do Programa de Pós-Graduação Stricto Sensu Territórios e Expressões Culturais no Cerrado (TECCER) da Universidade Estadual de Goiás (UEG)
} 
O funcionamento de tais unidades produtoras, contudo, requer a intervenção do elemento humano para seu gerenciamento. Por esta razão, grande parte dos estudos sobre a empresa capitalista moderna enfoca seu objeto sob o prisma de sua associação (forçosa) à figura do empresário.

Mas, quem vem a ser tal personagem? Que qualidades deve possuir um indivíduo para que seja tomado sob tal denominação? Que função (ou funções) desempenha na organização e funcionamento do conjunto da economia e da sociedade? Sobre tais pontos estabelece-se intrincada polêmica.

Para a finalidade a que se destina este trabalho, tomar como referência a personificação do capital na pessoa do empresário parece-nos medida indispensável. Isto porque, tem sido ele o elemento mediador típico (não obstante o papel do Estado) de tais processos no país, sob qualquer das formas particulares que tenha adquirido em nível regional ou local.

Assim, vamos dedicar atenção especial à decifração do personagem denominado empresário, mediante o exame de ideias a seu respeito desenvolvidas por autores hoje tidos como "clássicos" (além de "pioneiros") neste ramo de estudos. Embora sem perder de vista a referência de certos paradigmas teórico-metodológicos, vamos nos esforçar no sentido de apreender, da contribuição oferecida por esses autores, modelos e categorias mais diretamente relacionados com a função dinâmica das unidades de produção sob a ótica de seu vínculo com o empresário.

A compreensão de uma sociedade depende do exame das forças sociais aí presentes, representadas pelos seus diversos grupos. Nas condições históricas recentes, sob o capitalismo, a complexidade da dinâmica social não esconde uma distinção fundamental, ou seja, a que se estabelece entre os grupos aos quais vamos chamar (como em certa tradição historiográfica francesa), por conveniência, de "burguesia de empresa" e "operários de fábrica". Formam eles os grupos fundamentais das sociedades contemporâneas, dominando o cenário: "É em relação a eles que se regula e se determina, em certos momentos de escolha decisiva, a atitude dos grupos sociais próximos e intermédios" (BOUVIER, 1967, p. 284). Aqui, sob o "pano de fundo" que representa a consciência da complexidade alcançada pela dinâmica social na história contemporânea, é que vamos tomar, para efeitos de nossa reflexão, apenas o primeiro grupo mencionado. 
Mas, o que vem ser a "burguesia"? E, mais: "burguesia de empresa"? O termo "burguês", como se sabe, designava originalmente o cidadão de um burgo que gozava de status privilegiado - caracterizava-se pelas suas atividades lucrativas e por estar isento da execução de trabalho braçal ou artesanal. E hoje, o que deve ser entendido por esta palavra, para efeitos de uma análise histórica?

O termo "burguesia" evoca a noção de unidade e coesão de um grupo. Mas, que critérios são considerados para a inferência desta unidade? Ou, dito de outra forma: que condição ou condições são necessárias a um indivíduo, para que seja tomado como parte de tal unidade? Somente depois de resolvida esta questão, pode tornar-se possível a compreensão da segunda parte daquela noção sobre a palavra burguesia, isto é, o aspecto da coesão.

Devemos esforçar-nos, então, em deslindar aquele primeiro aspecto da questão. Já a própria definição de burguesia de Daumard fornece-nos alguns elementos importantes, que devemos registrar e desenvolver. Abrange indivíduos com qualificações definidas: os "capitalistas" e os que "são levados pelo espírito de empresa e de criação". Mas, há também uma outra condição, abrangendo elementos ao mesmo tempo próprios e externos a estes indivíduos, implicada no conceito: a da utilização das "possibilidades novas que dão o desenvolvimento do crédito, a industrialização [...]" (DAUMARD,1985, p. 12).

Quanto ao primeiro aspecto, o das qualidades próprias do individuo, vejamos antes o termo "capitalista". Pelo senso comum, o capitalista pode ser simplesmente um homem de dinheiro (possuidor de fortuna monetária) ou aquele que, detendo preliminarmente esta condição, aplica dinheiro em alguma transação que possa Ihe permitir, mais tarde, auferir um valor adicional por unidade de dinheiro aplicada. Isto vale tanto para o que especula com dinheiro, quanto para o que se estabelece na condição de proprietário de alguma unidade empresarial - agrária, industrial, comercial ou de serviços.

Quanto ao caso dos simples possuidores de riqueza monetária, seja o que entesoura ou o especulador, segundo Karl Marx, são apenas capitalistas em potencial. Para que uma dada soma em dinheiro venha a funcionar como capital, um primeiro movimento é a sua transformação em meios de produção e força de trabalho e, um segundo, é o processo de produção de mercadorias - ou seja, a transformação dos meios de produção em mercadorias. A riqueza monetária, embora seja pré-requisito do advento do capital, tomada isoladamente, 
é inteiramente improdutiva; portanto, não é capital (MARX, 1985, p. 263 e seguintes). Deste modo, na concepção de Marx, os proprietários dos meios de produção (aí incluídos os dos meios de intercâmbio) são capitalistas, certamente.

Quando se toma em consideração aqueles a quem Daumard se refere como "os que são levados pelo espírito de empresa e de criação", entra em pauta um novo termo: "empresário". Isto porque os autores que têm se dedicado ao estudo deste tema particular enfocam seus personagens a partir do prisma de sua relação indissociável com a empresa capitalista moderna.

Sob tal enfoque, a produção historiográfica é de tradição recente - surgiu no final dos anos 1920, na Universidade de Harvard. Em virtude disso, muitos dos seus conceitos não estão claramente formulados. Por outro lado, a circunstância desse ramo de estudos ter nascido em um meio acadêmico fortemente marcado pelo "ufanismo capitalista" (próprio da cultura norte-americana da época) resultou em que a maior parte dos trabalhos de que se compôs inicialmente fosse fortemente caracterizada pela tendência de se fazer a "apologia" do empresário.

Não desejando nos demorar na narração da história desse ramo de estudos, cabe mencionar, entretanto, que a partir dos anos cinquenta começou ele também a se firmar na Inglaterra e na França. O lançamento de periódicos especializados é uma demonstração disso - respectivamente, o jornal Business History e a revista Histoire des Entreprises (ambos em 1958) - e também a contribuição de estudos clássicos, como, por exemplo, os de Jean Bouvier - Crédit Lyonnais e Les Rothschild.

Contudo, seu desenvolvimento na Europa tem sido difícil. A destruição dos arquivos privados, as pressões políticas, a desconfiança dos homens de negócios em relação aos pesquisadores, etc., são algumas das razões pelas quais essa especialidade permaneceu, por muito tempo, como "alguma coisa especificamente americana" (CHABERT, 1954, p. 196; grifo nosso).

Em sua versão norte-americana, esse ramo de estudos consolidou-se mediante duas linhas diferentes de trabalho, segundo os métodos de abordagem empregados: a Business History (História dos Negócios ou de Empresa) e a Entrepreneurship History (História Empresarial ou da "função empresarial"). A fundação da primeira costuma ser atribuída ao 
professor N. B. S. Gras, responsável pela criação da cadeira de Business History em Harvard e grande incentivador do desenvolvimento desta área. Gras e seus seguidores dedicaram-se, principalmente, aos estudos biográficos de indivíduos de destaque no mundo dos negócios privados, no passado, sob o enfoque do exame das decisões administrativas e das políticas de controle destes negócios. Não obstante a natureza do meio em que vicejou, seu objetivo declarado era bem pouco acadêmico. A pretensão era, de acordo com Chabert (1954, p. 195), "proporcionar uma contribuição educativa à formação dos homens de negócios, primeiramente, e ademais, aos trabalhadores e ao grande público". Assim, "Eles perceberão", continua o autor, "mais perfeitamente, no futuro, os problemas próprios aos homens de negócios que assumem os riscos; se eles obtêm os benefícios, eles sofrem também as perdas.

Na atualidade, os seguidores dessa "escola", por vezes, inspiram-se em J. Schumpeter (precursor teórico em Harvard); porém, orientam-se, sobretudo, pelas ideias de Max Weber, a quem consideram o antecessor "mais eminente" e a quem atribuem o mérito da criação da ferramenta analítica mais "útil e eficaz", isto é: o "modelo ideal protótipo" (CHANDLER,1974, p. 32). De acordo com a tradição, o empresário é ainda visto na sua qualidade de promotor do progresso, se não o único, pelo menos o principal: "os norte-americanos [no último século e meio]", lembra Chandler, "experimentaram a transformação da economia agrário-rural em uma economia urbano-industrial tecnologicamente complexa [...]. Em todas estas mudanças, o empresário tem influído mais que os granjeiros, operários, tecnólogos, cientistas e até políticos ou funcionários de governo" (1974, p. 31; grifo nosso).

Numa outra linha, a Entrepreneurship History, fundada por A. H. Cole (também em Harvard), orientou-se no sentido de estudar empresários e empresas integrados ao contexto econômico, social e cultural de sua época, sob o ângulo das influências do ambiente histórico sobre o indivíduo e a unidade produtora a que estava vinculado e vice-versa. Interessava-se não apenas pelos grandes capitalistas, enquanto "individualidades", mas também pelos pequenos empresários e o meio que os produzia e em que atuavam. ${ }^{1}$

\footnotetext{
${ }^{1}$ Desde a década de 1960, a historiografia norte-americana de empresas vem sendo crescentemente dominada pela abordagem "organizacional" - ou "neo-institutionalist" -, sob a influência principalmente de Alfred Chandler - suas obras principais são Strategy and structure (1962), The visible hand (1977) e Scale and scope (1990). Tomando grandes empresas norte-americanas como modelos de análise, os estudos buscam a identificação dos mecanismos pelos quais se operou a "revolução organizacional" levada a efeito pelas grandes corporações modernas, caracterizada pela separação entre propriedade e administração, burocratização e eficiência
} 
A seguir, vamos rever, ainda que brevemente, o pensamento de dois pioneiros de Harvard, Joseph Schumpeter e Arthur Harrison Cole, cujas ideias têm-se constituído em referência obrigatória dos estudos nesse campo. Foram eles que estabeleceram e sistematizaram os critérios sob os quais, ainda hoje, grande parte dos autores (também fora dos Estados Unidos) qualifica o personagem "empresário" e define a sua função como agente histórico.

Depois, na tentativa de apreensão das características típicas do que veio a ser o empresariado brasileiro, sob as condições particulares de nosso desenvolvimento histórico, vamos nos deter sobre os estudos, também pioneiros, de Florestan Fernandes e José de Souza Martins, a respeito da formação da burguesia nacional, tomando-se como tipo social "protótipo", primeiramente, o homem de negócios de São Paulo e, secundariamente, o do Rio de Janeiro.

Chamamos a atenção, desde já, para o contraste das opções adotadas nas análises que vamos examinar, quanto aos ângulos de abordagem de um mesmo objeto. De um lado, a vertente norte-americana trata seu personagem coletivo, o "empresariado", sob uma ótica estritamente econômica, despindo-o de sua significação social e política, ou seja, da sua condição de "classe". De outro, os mencionados autores brasileiros observam-no privilegiando este seu outro ângulo, cujo caráter se acha imbricado no primeiro.

A opção pelo uso exclusivo de um dos termos "empresário" ou "burguês" (ou, "empresariado" em alternativa a "burguesia") não é destituída de significado. Estas palavras (com suas derivações) portam, em si, sentidos distintivos - não destituídos de conteúdo ideológico, quase sempre -, quanto à perspectiva pela qual se está olhando o indivíduo (ou grupo).

Uma terceira escolha (feita por Martins, por exemplo) é a de uso dos dois termos em relação a um mesmo personagem, ora tratando-o sob o ângulo de sua função técnica (a administrativa) no interior do empreendimento - na condição de "empresário", portanto ora sob o aspecto de suas relações e identificação sociais exteriores à unidade administrativa, que é onde se revela o "burguês".

administrativas, progresso tecnológico, alargamento dos mercados, etc. Na Europa, as experiências de pesquisa realizadas têm sofrido forte influência desta tendência norte-americana. 


\section{O ponto de vista dos "clássicos" na vertente norte-americana}

Jean-Baptiste Say é o pensador clássico em cujos conceitos se inspiram muitos dos estudos acerca do empresariado. Foi ele quem formulou, clara e suscintamente, a noção do que tradicionalmente se entende por empresário. (SAY apud COLE, 1946, p. 3-4)

Hugh Aitken traduz as ideias de Say a respeito de tal indivíduo, resumindo-as no seguinte conceito: "um empresário é aquele que adquire os fatores de produção a um determinado preço, combina-os e vende o resultado a um preço incerto." (AITKEN, 1974, p. 16). Utiliza-se deste recurso para realçar três pontos daquelas ideias: a) a ênfase no elemento humano - os fatores de produção exigem a intervenção do homem, para sua combinação; b) a incerteza quanto ao preço de venda e seus riscos - o transitar entre o seguro e o incerto; c) a função de produzir, em que está incluído o aspecto da escolha deliberada.

Aitken também resume sua interpretação acerca da noção de Say sobre as qualidades e a função próprias a esse indivíduo, do seguinte modo: "concebe o empresário como a pessoa que toma decisões, que é organizador e coordenador. Não menos importante é o fato de que, em sua opinião, o processo econômico no mundo real exige este agente." (AITKEN, 1974, p. 16). Neste último caso, ele está pretendendo contrapor o pensamento de Say à teoria econômica "anglo-norteamericana" clássica, que pouca importância atribui ao empresário os economistas que a representam seriam portadores de uma "estrutura de pensamento de caráter essencialmente mecânico" (AITKEN, 1974, p. 23).

Segundo o modelo clássico inglês, aqueles a quem Say denominava de empresários seriam uma categoria especial de força de trabalho. Na interpretação de Aitken, este tipo de empresário pode ser identificado com o dono de um armazém de bairro, na sua prática rotineira de combinar "fatores de produção de acordo com normas já conhecidas e vigentes." (AITKEN, 1974, p. 19). A esta noção, contrapõe o conceito de Schumpeter, que ele interpreta assim: "por empresariado se entende o ato de inovar, a resposta criativa [...] mediante a qual fluem para além do conhecido e vigente para internar-se no âmbito de novas possibilidades." (AITKEN, 1974, p. 18; grifo nosso.).

Os elementos "inovação" e "aventura" são chave na concepção clássica norteamericana acerca do que vem a constituir a essência do empresariado. A respeito do assunto, 
são estas as palavras de Cole: "Na análise de Say falta ênfase no espírito de aventura e o elemento inovação, sem os quais, para mim, uma completa formulação da função empresarial é impossível." (COLE, 1946, p. 4).

Vamos examinar, primeiro, as ideias de J. Schumpeter a respeito do empresariado, não exatamente em razão de ter ele se antecedido cronologicamente a Cole, mas porque elas tiveram grande influência sobre o pensamento deste último - razões adicionais poderiam ser a repercussão que tiveram, em sua época, as ideias do primeiro a respeito de desenvolvimento econômico e o fenômeno mais recente da ressurreição de algumas delas na formação do ideário neoliberal.

Schumpeter necessitou do conceito de empresariado para explicar o desenvolvimento econômico que, para ele, representava a introdução de novas funções de produção, novos produtos, etc. e a abertura de novos mercados. Entendia por desenvolvimento a ocorrência de uma mudança "revolucionária" na vida econômica, vinda de dentro dela mesma, surgida de sua própria iniciativa: "é uma mudança espontânea e descontínua nos canais de fluxo, perturbação do equilíbrio que afeta e desloca para sempre o estado de equilíbrio previamente existente" (SCHUMPETER,1982, p. 47).

Tais mudanças ocorreriam nas esferas industrial e comercial e não na das necessidades dos consumidores. Diz ele: “[...] desprezamos qualquer espontaneidade das necessidades dos consumidores [...] admitiremos que os gostos são 'dados' [...] é o produtor que, via de regra, inicia a mudança econômica, e os consumidores são educados por ele, [...] ensinados a querer coisas novas" (SCHUMPETER, 1982, p. 48).

O desenvolvimento, em Schumpeter, é definido pela realização de novas combinações dos meios de produção; denota "combinar materiais e forças que estão ao nosso alcance. Produzir outras coisas, ou as mesmas coisas com método diferente, significa combinar diferentemente esses materiais e forças [...]." (SCHUMPETER,1982, p. 48). A produção segundo novas combinações, novos métodos, é realizada, via de regra, por empresas novas e não pelas já estabelecidas. As pessoas que corporificam as novas combinações, em geral, não são as mesmas que controlam o processo produtivo ou comercial já existente. 
Ao fenômeno fundamental do desenvolvimento, a realização de combinações novas, Schumpeter chama de "empreendimento"; aos indivíduos cuja função é realizá-las, chama de "empresários". Porém, ele chama de "empresários" não apenas aos homens de negócios "independentes", mas a "[...] todos que de fato preenchem a função pela qual definimos o conceito, mesmo que sejam [...] empregados 'dependentes' de uma companhia, como gerentes, membros da diretoria etc., ou mesmo se o seu poder real de cumprir a função empresarial tiver outros fundamentos, tais como o controle da maioria das ações". (SCHUMPETER, 1982, p. 54)

Industriais, comerciantes, dirigentes de empresas e gerentes que simplesmente operam um negócio já estabelecido estão excluídos desse conceito. De modo idêntico, o acionista comum não é considerado um empresário enquanto tal - Schumpeter descarta a concepção de empresário como aquele que corre riscos. Ele também faz distinção entre empresários e capitalistas, "independentemente de os últimos serem vistos como proprietários de dinheiro, de direitos ao dinheiro, ou de bens materiais"; e aponta que expressões como "iniciativa", "autoridade" ou "previsão" concorrem para o seu conceito (SCHUMPETER, 1982, p. 48).

Aceita a noção de J. B. Say, de que a função do empresário é reunir e combinar os fatores produtivos, porém, com a seguinte ressalva: "Como essa atuação é de tipo especial apenas quando os fatores são combinados pela primeira vez [...] essa definição coincide com a nossa." (SCHUMPETER, 1982, p. 54). Um indivíduo só é empresário na ocasião em que efetua novas combinações, perdendo este caráter assim que passa a se dedicar à administração do negócio montado. Entretanto, "é tão raro alguém permanecer sempre como empresário [...] quanto é raro um homem de negócios nunca passar por um momento em que seja empresário, mesmo que seja em menor grau." (SCHUMPETER, 1982, p. 56)

Schumpeter diferencia quatro tipos sociais, quais sejam: o empresário, o capitalista, o administrador e o inventor. Destes, o último é o que tem para ele menor interesse; isto porque, enquanto não forem levadas à prática, "as invenções são economicamente irrelevantes [...]. Além disso, as inovações, cuja realização é a função dos empresários, não precisam necessariamente ser invenções." (SCHUMPETER, 1982, p. 62)

Segundo ele, o curso dos acontecimentos desenvolveu, paulatinamente, um tipo social que incorpora a função empresarial com uma "pureza particular": trata-se do tipo 
moderno de "capitão de indústria". A realização de combinações novas é privilégio de um tipo especial de pessoa, muito menos numeroso do que o daquelas que têm a possibilidade "objetiva" de fazê-lo. Os empresários representam este tipo e, nesta condição, são a "força motriz" do desenvolvimento econômico.

Os empresários não surgem individualmente e de modo continuado, ao longo do tempo, mas, "aos magotes". Isto, porque o aparecimento de um, ou de uns poucos, facilita o aparecimento de outros; estes provocam o de mais outros e assim por diante. Na teoria do "ciclo econômico" de Schumpeter, o aparecimento de empresários em grupos é a causa do boom. Segundo ele:

[...] todo boom é seguido por uma depressão, toda depressão por um boom [...] o boom termina e a depressão começa após a passagem do tempo que deve transcorrer antes que o produto dos novos investimentos possa aparecer no mercado. E um novo boom se sucede à depressão, quando o processo de reabsorção das inovações estiver terminado." (SCHUMPETER, 1982, p. 142)

Schumpeter cunhou a expressão "destruição criadora" para designar o processo pelo qual cada avanço tecnológico, ao criar novas formas de produção, provoca a destruição das antigas, por obsolescência. Este processo ocorre porque, "[...] em regra, o novo não nasce do velho, mas aparece ao lado deste e o elimina na concorrência [...]" (SCHUMPETER,1982, p. 143).

Pela ótica de Schumpeter, os empresários não formam uma classe social, dada a transitoriedade desta condição. Contudo, a função empresarial levará o empresário bem sucedido (e sua família) a certas posições de classe que, não se caracterizando como empresarial, podem corresponder às de capitalista. Os capitalistas, sim, são os que formam uma classe social no sentido "técnico" do termo.

Arthur H. Cole foi o responsável pela mudança da palavra Business para a outra, Entrepreneurship. E isso, por si só, é já considerado significativo. Em sua teoria, distinguem-se os seguintes pontos: a) sob influência de Schumpeter, estabelece diferenciação entre o empresário e o capitalista; b) advoga, insistentemente, pela investigação da empresa no contexto do meio social ao qual pertence; c) defende a interferência do Estado na economia. 
A concepção de Cole a respeito do empresário pode ser interpretada como uma síntese das de Say e Schumpeter. Descreve o empresariado como "uma sequência integrada de ações, levadas a efeito por indivíduos ou grupos que atuam para unidades administrativas individuais, dentro de um mundo caracterizado, em larga medida, pela incerteza." (COLE, 1946, p. 4).

Cole e seu grupo, inspirando-se diretamente em Schumpeter, viam o homem de negócios não tanto como administrador, mas principalmente como inovador; acrescem a isso a noção de que o empresariado representa um processo social. Viam o empresário norteamericano não apenas pelo prisma do seu esforço pessoal, mas também pelo ângulo da sua função social, na qualidade de criador do progresso econômico.

Entendiam que o desenvolvimento das empresas depende da existência de um meio social predisposto favoravelmente a elas, no qual a posição social do empresário seja apreciada (COLE, 1946, p. 11). Com este clima favorável, o fator significativo passa a ser o desenvolvimento da habilidade de se tomar "decisões sábias relativas à inovação, administração e ajustamento das forças externas" (COLE, 1946, p. 11). Em tais forças externas, Cole inclui a imitação, por parte de algumas empresas, de inovações iniciadas por outras que, direta ou indiretamente, competem com as primeiras; inclui, também, a extensão de inovações a unidades administrativas ligadas às originalmente inovadoras por interesses subsidiários ou subordinados.

Seus estudos marcam a passagem da noção de empresário individual à de empresário coletivo - "Estamos interessados em uma pessoa [...] ou em muitas pessoas que sozinhas [...] ou como uma junta empreendedora, conduzem o destino de cada empresa." $E$, a exemplo de Schumpeter, inclui os executivos na sua concepção de empresário. Contudo, seu interesse era, principalmente, pelos "executivos de topo" ou "administradores de topo" (COLE, 1946, p. 5).

Na visão de Cole, os empresários constituem um quarto fator produtivo. Em termos simplificados, definiu o empresariado como "a utilização por um fator produtivo de outros fatores produtivos, para a criação de bens econômicos" (COLE, 1946, p. 4). E, numa declaração frequentemente citada, disse: "Estudar o `empresário' é estudar a figura central da história econômica, e, na minha forma de pensar, a figura central da economia" (COLE, 1946, p. 8). 
Não obstante as peculiaridades da orientação seguida por Cole e seu grupo, no sentido de tornar sua especialidade um ramo de estudos das ciências sociais, a preocupação com o aspecto pragmático da viabilização material de suas pesquisas esteve presente. Cole esperava que esta área viesse a se constituir em ponto de convergência de interesses entre historiadores econômicos e homens de negócios. (FREITAS FILHO, 1989, p. 141). Aí estão em jogo, frequentemente, além da questão do financiamento, também a do acesso à documentação das empresas que, no capitalismo liberal, gozam do privilégio da manutenção de sigilo a respeito de grande parte dos aspectos abrangidos em seus negócios.

\section{O burguês e o empresário no Brasil segundo os estudos pioneiros}

Entre os estudos pioneiros sobre a formação da burguesia no Brasil, dois são clássicos na sua condição de teóricos (embora sejam também empíricos, em grau diverso um do outro): "A Revolução Burguesa no Brasil", de Florestan Fernandes e "Conde Matarazzo, o empresário e a empresa", de José de Souza Martins. Este último autor, na sua obra "O Cativeiro da Terra", retoma alguns pontos fundamentais daquele seu trabalho anterior, desenvolvendo novas e mais amplas reflexões acerca deles.

Segundo Fernandes, no Brasil, o burguês já surgiu como uma "entidade especializada"; está ele se referindo ao "agente artesanal" - aquele inserido na rede de mercantilização interna - e ao negociante. Durante o período colonial, estas figuras permaneceram destituídas de significado, sufocadas pela estreiteza do mercado interno. Com a Independência, enquanto o primeiro submergia, devido à absorção de suas funções pelas casas importadoras, o grupo dos comerciantes, expandindo-se e diversificando-se, passava a formar o "núcleo burguês" da típica cidade brasileira do século XIX. Estes fatos relacionaramse, inicialmente, com o crescimento do comércio e a formação de uma rede de serviços ligada à organização do Estado nacional e, mais tarde, com o desenvolvimento urbano no país.

Com o processo de incorporação da economia brasileira ao sistema econômico colonial moderno - "neocolonial" -, desenvolveu-se o primeiro surto de renovação econômica interna, de fato. Aí, pela primeira vez, "emergia na cena histórica brasileira o verdadeiro palco do 'burguês': uma situação de mercado que exigia, econômica, social e politicamente, o 'espírito burguês' e a 'concepção burguesa de mundo'" (FERNANDES, 1987, p. 96). Agora, o excedente da economia agrária "patrimonial" deixava de ser entesourado ou destinado 
apenas à preservação do quadro produtivo tradicional e passava a ser consumido, depositado a juros ou aplicado na cidade. Esta mudança refletiu-se em transformações tanto na produção como no consumo.

Com esta passagem do entesouramento e da propensão a economizar - modalidades de acumulação pré-capitalistas - à acumulação capitalista propriamente dita, iniciava-se o processo que levaria ao fenômeno a que Fernandes denomina de "Revolução Burguesa": "[...] conjunto de transformações econômicas, tecnológicas, sociais, psicoculturais e políticas que só se realizam quando o desenvolvimento capitalista atinge o clímax de sua evolução industrial" (FERNANDES, 1987, p. 203).

A revolução burguesa brasileira, então, não constituiu um episódio histórico, mas sim um fenômeno estrutural em que a sociedade nacional absorveu um tal padrão de civilização que resultou na conversão da "Revolução" numa necessidade social e histórica. E, para que haja uma revolução social, em qualquer parte e tempo, são exigências: a) que exista na sociedade "certas categorias de homens, capazes de atuar socialmente na mesma direção, com dada intensidade e com relativa persistência"; b) que "essas categorias de homens disponham de um mínimo de consciência social, de capacidade de ação conjugada e solidária e de inconformismo em face do status quo, para poder lidar, coletivamente, com 'meios' e 'fins' como parte de processos de reconstrução social." (FERNANDES, 1987, p. 21)

O processo de consolidação do capitalismo, no Brasil, abrangeu duas fases, isto é, uma primeira, de ruptura da homogeneidade da "aristocracia agrária", e uma segunda, a do aparecimento de novos tipos de agentes econômicos sob a pressão da divisão do trabalho nas escalas local, regional e nacional.

Em todos os lugares nos quais ocorreu a "revolução burguesa", ela foi protagonizada por agentes históricos que exerciam papéis estratégicos para a formação e o desenvolvimento do capitalismo. No Brasil, "os agentes humanos impregnados de interesses, aspirações e valores sociais que deram sentido às suas ações e relações econômicas foram o fazendeiro do café e o imigrante" (FERNANDES, 1987, p. 98; grifo nosso).

O capitalismo brasileiro, entretanto, não tinha as mesmas características "estruturais e funcionais" do capitalismo clássico. Tratava-se de um capitalismo de tipo especial, estabelecido sobre uma estrutura de mercado que possuía duas dimensões: "uma 
estruturalmente heteronômica; outra com tendências econômicas autonômicas ainda em vias de integração estrutural". Devido a esta dupla polarização, Fernandes aplica a este capitalismo a noção de "capitalismo dependente" (FERNANDES, 1987, p. 90).

O burguês típico é uma "entidade" que, no Brasil, apareceu tardiamente e segundo um curso distinto do que foi seguido na evolução da Europa. Contudo, surgiu dentro de condições que "prefiguram funções e destinos sociais análogos, tanto para o tipo de personalidade quanto para o tipo de formação social." (FERNANDES, 1987, p. 17).

O fazendeiro de café, variante típica do antigo senhor rural, logo dissociou a fazenda e a riqueza que ela produzia do "status senhorial". Passou, de modo sistemático e direto, a procurar a riqueza "em si e por si". Só mais tarde veio a utilizar a riqueza como fonte e símbolo de poder. A grande fazenda de café transformou-se rapidamente numa variação da plantation tropical moderna, associada à acumulação de capital, tanto comercial como financeira.

Fernandes descreve variados tipos de fazendeiros de café: o "fazendeiro barão", o que reproduzia o modelo de "personalidade-ideal" do antigo senhor de engenho, o que procurava encarnar a "personalidade-ideal" do moderno homem de negócios urbano, o "coronel" (este, surgido mais tardiamente), etc. Todos eles, entretanto, adotavam uma conduta comum, isto é, sistematicamente, deslocavam o excedente econômico que não podia ser aplicado na grande lavoura para atividades econômicas urbanas. Deste modo, concorriam, permanentemente, para a expansão de um setor que se chocava, frontalmente, com os interesses, as concepções de mundo e as formas de dominação até então vigentes.

Se havia vários tipos de fazendeiros, a diversidade com relação ao imigrante era ainda maior. A variedade das correntes migratórias e das formas de sua incorporação à economia interna produziram tal resultado. O imigrante por quem se interessa Fernandes, neste caso, é aquele cuja perspectiva é a de acumular fortuna, preferencialmente, sob a forma monetária.

Os meios para a acumulação de capital acessíveis ao imigrante comum giravam em torno da metamorfose do trabalho em dinheiro; mas, nem sempre, do trabalho pessoal ou de uma forma constante de trabalho. A forma mais simples era a da cooperação doméstica, que permitia o aumento da produtividade do trabalho e a intensificação da apropriação individual do excedente econômico produzido pela família ou pela parentela. 
No sistema de parceria vigente nas fazendas de café, os imigrantes podiam desenvolver, ao mesmo tempo, uma esfera independente de comercialização constante de bens de consumo. Aqueles que conseguiam atingir certo patamar de êxito geralmente abandonavam a condição de trabalhador passando a tentar modalidades de mascateação, de pequeno comércio ou de produção artesanal, etc. Em dado ponto, enfim, alguns deles conseguiam alçar voo, aventurando-se no terreno da produção industrial.

Este novo agente, entretanto, atuava de forma "diligente, pertinaz e construtiva" apenas no âmbito mais estreito de seus interesses imediatos. Não projetaria tais interesses por falta de razões emocionais, morais ou materiais - em planos mais amplos, nem tentaria explorar outras formas de racionalidade econômica, que pudessem associar as atividades econômicas a ideais coletivos de independência e autossuficiência da economia nacional. Fernandes julga que este aspecto pode ter se constituído no ponto fraco do ulterior desenvolvimento do capitalismo no Brasil.

Apesar disto, o imigrante foi o principal agente econômico do novo sistema porque: a) coube a ele a função de "agente original de trabalho livre", primordial para a constituição de uma economia capitalista (monetária e de mercado); b) era o único elemento que possuía expressão monetária e poder aquisitivo real; c) ocupou posição central na "canalização socialmente construtiva de influências dinâmicas, que faziam pressão sobre a diferenciação e a intensificação da produção destinada ao consumo interno." (FERNANDES, 1987, p. 143-144).

No desenvolvimento das atividades dos protagonistas do novo regime econômico, houve uma espécie de especialização invisível: “Enquanto o fazendeiro só exercia funções relevantes para a expansão do capitalismo nas posições que estavam no ápice da estrutura econômica, o imigrante fazia o mesmo em todas as posições possíveis, de 'assalariado' a 'homem de negócios'" (FERNANDES, 1987, p. 144).

$\mathrm{Na}$ acepção em que usa Fernandes a expressão "Revolução Burguesa", como fenômeno estrutural e de longo prazo, existe (segundo ele próprio) um ponto de partida e um ponto de chegada, sendo extremamente difícil localizar-se o momento em que este processo alcança "um patamar histórico irreversível, de plena maturidade e, ao mesmo tempo, de consolidação do poder burguês e da dominação burguesa" (FERNANDES, 1987, p. 203; grifos dos autores). No seu ponto de vista, todavia, os processos de transição ao século XX e de 
industrialização desenrolados até a década de 1930 foram parte fundamental da evolução interna do capitalismo competitivo, cujo eixo estava no esquema de exportação e importação.

Nesse processo, segundo ele, a cidade converteu-se no polo dinâmico do desenvolvimento capitalista interno. O incremento constante das populações urbanas, especialmente das cidades-chaves - Rio e São Paulo - constituiu-se no lastro interno para o "crescimento natural" do mercado capitalista moderno e forneceu as bases da reorganização geográfica, econômica, sociocultural e política exigida para a expansão de tal mercado. Ao campo, entretanto, não se estendia qualquer desdobramento do que Fernandes chama de "revolução urbana".

Aliás, o que vinha sendo descrito, até aqui, refere-se ao que Fernandes chama de "início da modernidade" no Brasil, tendo como núcleo espacial o eixo Rio-São Paulo. Quanto às outras regiões brasileiras, o que as caracterizava,

[...] era é o seu tom cinzento e morno, o seu tom vacilante, a frouxidão com que o País se entrega, sem profundas transformações iniciais em extensão e em profundidade, ao império do poder e da dominação nascidos do dinheiro. $\mathrm{Na}$ verdade, várias burguesias (ou ilhas burguesas), que se formaram em torno da plantação e das cidades, mais se justapõem do que se fundem, e $o$ comércio vem a ser o seu ponto de encontro e a área dentro da qual se definem seus interesses comuns." (FERNANDES, 1987, p. 204. Grifo nosso).

Finalizando, devemos ainda realçar que, segundo Fernandes, em nenhuma das fases do desenvolvimento capitalista no Brasil impuseram-se: a) a ruptura da associação dependente com o exterior; b) a desagregação completa do "antigo regime" (quanto a formas pré-capitalistas de produção, troca e circulação); c) a superação de "estados relativos de subdesenvolvimento, inerentes à satelitização imperialista da economia interna e externa" (FERNANDES, 1987, p. 223).

José de Souza Martins aborda a questão da burguesia brasileira por dois ângulos distintos. Por um, no trabalho em torno do caso Matarazzo, o enfoque é sobre as características institucionais do desenvolvimento industrial brasileiro, ora examinando aspectos relativos àquele grupo econômico, ora analisando as condições da industrialização em São Paulo e no Brasil. Por outro, no livro O Cativeiro da Terra, o ponto central da discussão é o das formas engendradas pelo capital para garantir sua própria expansão, nas condições históricas brasileiras, aí incluído o processo de incorporação da economia nacional ao capitalismo industrial. Vamos tomar, primeiro, este último enfoque, em razão do seu caráter 
mais abrangente em relação ao outro. Sob tal enfoque, o eixo central da análise recai sobre a questão da forma de ser do capital da fazenda de café.

Para Martins, a principal forma de capital da fazenda de café era a da renda capitalizada da terra, tanto sob o trabalho escravo, como sob o trabalho livre. Isto permitiu ao fazendeiro que, convertendo a sua atividade rural em um empreendimento baseado em relações de produção não capitalistas, pudesse tornar-se, também, um empresário capitalista. Ele examina a questão da origem do capital do fazendeiro paulista - principalmente o de café, mas também o da cana-de-açúcar e o de algodão - sob o prisma da teoria marxista da renda territorial na sociedade capitalista:

Sendo a renda da terra de origem pré-capitalista, perde, no entanto, esse caráter à medida que é absorvida pelo processo do capital e se transforma em renda territorial capitalizada, introduzindo uma irracionalidade na reprodução do capital. A determinação histórica do capital não destrói a renda nem preserva o seu caráter pré-capitalista _ transforma-a, incorporando-a, em renda capitalizada (MARTINS, 1986, p. 3).

Fez desta noção uma hipótese, abrangendo, além das relações pré-capitalistas, também as relações não capitalistas de produção, para examinar o regime do "colonato" nas fazendas de café e, ao mesmo tempo, a origem da industrialização de São Paulo. Na formulação dessa hipótese, colaborou também a consideração da palavra "fazenda" no seu sentido coevo àqueles acontecimentos; ou seja, significando o conjunto de bens de um dado indivíduo, a sua riqueza acumulada e, principalmente, os bens produzidos pelo trabalho. Neste caso, a palavra fazenda estava "muito próxima da noção de capital e muito longe da de propriedade fundiária", seu sentido atual (MARTINS, 1986, p. 23).

Martins descreve o colonato como um regime de trabalho "singular" constituído historicamente no processo de substituição do trabalho escravo, em atendimento às necessidades do capital. Caracterizava-se pela combinação de três componentes: um pagamento fixo pelo trato do cafezal; um pagamento proporcional à quantidade de café colhida; e terra para trabalho, na produção de gêneros de subsistência. Esta última condição permitia ao colono a produção de excedentes comercializáveis.

Segundo ele, o colonato não pode ser definido como um regime de trabalho assalariado, pelos seguintes motivos: primeiro, porque "o salário em dinheiro é, no processo capitalista de produção, a única forma de remuneração da força de trabalho"; depois, porque "o colono não é um trabalhador individual, mas sim um trabalhador familiar"; e, por último, 
em razão de ao colono ser permitida a "produção direta dos meios de vida, com base no trabalho familiar". É esta última condição, todavia, que impossibilita, definitivamente, que se considere esse regime de trabalho como constituído de relações capitalistas de produção (MARTINS, 1986, p. 18-19). Assim, então, sua análise parte da premissa que "o capitalismo, na sua expansão, não só redefine antigas relações, subordinando-as à reprodução do capital, mas também engendra relações não capitalistas igual e contraditoriamente necessárias a essa reprodução" (MARTINS, 1986, p. 22).

O capitalismo estabelece relações não capitalistas de produção como meio de garantir sua própria expansão nos lugares e nos setores que se vincularam à economia capitalista mediante relações comerciais. A referência fundamental de Martins, no trabalho aqui em pauta, é a questão dos ritmos e das formas de disseminação do capitalismo, frequentemente referida por Karl Marx para indicar que as relações capitalistas de produção, uma vez instauradas, disseminam-se lentamente por todas as partes. Martins está se referindo ao caráter mundial do capitalismo.

Por esta razão, considera que as relações sociais que engendraram o fazendeirocapitalista não foram apenas as relações de produção, dentro da fazenda, mas também, e "significativamente", as relações que mantinha, fora da fazenda, com os comissários de café e, já no final do século XIX, com os exportadores.

Na concepção de Martins, no caso brasileiro, o processo básico de "acumulação primitiva" - a separação do trabalhador dos seus meios de produção - ocorreu fora do país: "a expropriação capitalista, com a sua característica violência (...) enquanto processo vivido pessoalmente e subjetivamente pela maioria dos próprios trabalhadores (imigrados para o Brasil) deu-se fora da sociedade brasileira." O Brasil recebeu este trabalhador "livre", sem ter feito antes a acumulação responsável pela sua "libertação" (MARTINS, 1986, p. 118-119).

A respeito da explicação, comum a vários autores, de que a indústria teria surgido para substituir importações nos períodos críticos da comercialização do café, Martins constatou que ela já existia antes da ocorrência daquelas crises e, então, adotou (com base em ampla pesquisa empírica em torno do caso Matarazzo, abrangendo vários grupos pioneiros) uma nova posição a respeito da gênese da indústria nacional: “[...] a indústria brasileira não surgiu no próprio corpo das relações imediatamente produzidas pelo comércio de produtos coloniais, como o café, mas sim nos interstícios dessas relações, à margem e 
contra o circuito de trocas estabelecido pelos importadores" (MARTINS, 1986, p. 106; grifo dos autores).

A origem da indústria nacional esteve vinculada, segundo ele, a um complexo de relações e produtos que não pode ser reduzido ao binômio café-indústria. Na realidade, praticamente todos os grupos que vieram a se tornar grandes, depois, surgiram no último quarto do século XIX e apareceram para substituir a produção artesanal doméstica ou, então, a pequena manufatura.

Esta última desenvolvia-se no Estado de São Paulo, em grande número de estabelecimentos, distribuídos entre a capital e muitos municípios do interior. Só depois do Encilhamento (no começo dos anos 1890), ocasião em que houve uma intensa atividade econômica na cidade de São Paulo, os estabelecimentos passaram a se concentrar na capital e em alguns municípios mais importantes. A indústria nasceu, então, para substituir a pequena produção intersticial e não para substituir importações. Substituiu, em realidade, a produção artesanal doméstica e a produção organizada em pequena escala.

Por outro lado, no período crucial para a gênese da indústria em São Paulo (que Martins localiza entre 1870 e 1905), eram poucos os fazendeiros que se dedicavam à atividade industrial. Além de suas fazendas, eles se ocupavam de diferentes negócios como ferrovias, bancos, comércio em geral, comércio imobiliário e, também, indústria. Mas, em todos eles, sobretudo como pequenos acionistas, juntamente com outro grande número de investidores. Martins reconhece, todavia, que diversos desses fazendeiros, mesmo como pequenos acionistas de empresas do tipo sociedade anônima - bancos e ferrovias, principalmente -, eram também seus diretores. Segundo ele, porém, a industrialização no Brasil relaciona-se, sobretudo, à supressão do trabalho escravo e à imigração estrangeira, pelo alargamento da faixa dos "consumidores-compradores" que tais fatos representaram: "Surgia um acréscimo de mercado que não podia ser atendido pelo comércio importador, mas que podia servir-se de sucedâneos mais precários dos produtos importados, produzidos aqui mesmo" (MARTINS, 1976, p. 65).

O fato de a indústria ter surgido na área da economia do café - Rio de Janeiro e São Paulo - explica-se pelo crescimento populacional ocorrido aí para atender à expansão da cafeicultura. A mão de obra que se importou para concentração nessa área, entretanto, não era apenas de procedência estrangeira, mas incluía também o elemento nacional. 
Por outro lado, o trabalho livre libertou o consumidor das restrições impostas pela sua ligação direta com o fazendeiro - que comprava por si, por seus escravos e também por seus agregados livres. Em tal situação, o mercado dimensionava-se em função das possibilidades de consumo dadas pela "empresa" agrária e pelo afã de lucro do fazendeiro. Agora, "o consumo passou a ser função, não mais da empresa, mas das possibilidades diretas do consumidor. Multiplicou-se o número de decisões necessárias à aquisição de mercadorias [...]" (MARTINS, 1976, p. 72)

A viabilidade da industrialização, deste modo, não teve relação direta com as crises do comércio exterior. Contudo, "o industrial só podia atuar, com ou sem crises, se pudesse romper o domínio dos grandes comerciantes ou aproveitar as brechas na sua atuação" (MARTINS, 1976, p. 75). A alternativa que a indústria encontrou para romper com o domínio dos importadores e, assim, obter acesso ao consumidor, foi a do investimento paralelo no grande comércio; com isto, "a industrialização fez-se como atividade precipuamente mercantil e com largas características monopolistas" (MARTINS, 1976, p. 76). O caso do grupo liderado pelo Conde Matarazzo é um exemplo típico da atividade industrial associada, secundariamente, a grandes empreendimentos comerciais.

No estudo que Martins faz deste caso, tomado na dimensão indissociável das condições históricas em que ocorreu a implantação da indústria no Brasil, entre outros aspectos, ele examina a questão ideológica e das representações, que permeia a atuação empresarial e política de um novo segmento da sociedade, a que ele denomina de "burguesia industrial". Muito embora a dimensão ideológica da constituição das classes sociais não se constitua em ponto focal deste trabalho, vale a pena tomar-se aqui, rapidamente, alguns elementos de sua análise, úteis à compreensão do que ele entende por tal denominação e, sobretudo, pelo termo "burguesia".

Para Martins, a personalidade e a conduta desse tipo humano - o industrial -, que "age em consonância com os requisitos do capital", desdobra-se em duas racionalidades distintas: a do "empresário" e a do "burguês". Na primeira condição, "sua ação é centrípeda, é referida aos ajustamentos sócio-culturais no interior do empreendimento". Aí estão em causa a racionalidade requerida à produção industrial e o "papel especificamente técnico" do empresário. Na segunda condição, a de "burguês", "como sujeito identificado exteriormente com as implicações do sistema na realização do lucro, e neste sentido, identificado com a 
burguesia agro-comercial, como forma de sobrevivência, é que podemos apreender o sentido das ações do tipo". É nesta última dimensão que se define o "capitalista" (MARTINS, 1976, p. 108-109).

Segundo Martins, o recurso a este desdobramento foi o que the permitiu compreender porque a burguesia industrial "exteriorizava-se" como burguesia comerciante (composta com outros setores da burguesia). Na "fase comercial" da industrialização brasileira, o lucro não residia, necessariamente, no processo produtivo, mas na comercialização do produto. Então, o lucro, "na atividade industrial, tem por base a racionalidade dominante - a racionalidade da sociedade agrário-exportadora" (MARTINS, 1976, p. 109-110; grifo nosso).

\section{Conclusão}

Para concluir, retomemos brevemente a discussão que travamos atrás a respeito do uso dos termos "empresário" e "burguês". Apontamos para o fato de a corrente historiográfica norte-americana ter tomado o empresariado sob o ângulo exclusivamente econômico, despojando-o da sua condição de classe - tal opção, visivelmente, não esteve destituída de uma intenção ideológica. Diferentemente disto, Fernandes examina o homem de negócios (e o de dinheiro), no Brasil, na perspectiva do sistema de classes sociais, aplicando a ele o termo "burguês". Um terceiro caminho foi seguido por Martins, isto é, usa o termo empresário quando está se referindo à função técnica (a administrativa) desse indivíduo, no interior da unidade produtora, e emprega a denominação "burguês" nas ocasiões em que examina as formas pelas quais tal personagem se "exterioriza" e se identifica em relação à sociedade circundante e seus diversos segmentos.

Entendemos que, na realidade, empresário e burguês não são a mesma coisa, muito embora haja um conjunto importante de casos em que estes dois conceitos se aplicam a um mesmo indivíduo. Em certa parte deste trabalho, referimo-nos ao fato da palavra "burguesia" evocar as noções de unidade e coesão. O fator que se tornou o denominador comum desse conjunto de indivíduos foi a posse da riqueza; contudo, não, necessariamente, transformada em capital, isto é, meios de produção e força de trabalho - talvez Marx não tenha feito distinção entre capitalistas e empresários porque, em sua época, um mesmo indivíduo era, em regra, ambas as coisas. Na sociedade capitalista moderna, a função de transformar 
dinheiro em capital é própria ao empresário. E este, na era do capitalismo financeiro, frequentemente, lança mão do dinheiro alheio, antes que do seu próprio.

O aspecto da coesão manifesta-se na burguesia (assim como no proletariado) quando ela adquire consciência dos interesses e objetivos comuns ao grupo, no seio de um sistema de classes antagônicas, ou seja, forma-se, lentamente, no desenvolvimento de seu antagonismo em relação à outra classe, embora a composição de tal grupo possa ser muito heterogênea (de classe em si passa a classe para si, segundo Marx).

Vale também notar, que nossa opção pelo uso do termo empresariado, em vez de burguesia, deve-se ao fato do enfoque adotado na pesquisa recair sobre os mecanismos de produção e reprodução do capital, implicados nas atividades econômicas próprias ao mundo contemporâneo. Uma outra discussão diz respeito à questão das decisões econômicas, que obedecem a uma regularidade possível de ser descoberta, decorrente da determinação social dos atos de eleição e também da limitação prática das possibilidades de escolha. Isto não significa, realcemos, que haja uma ausência absoluta da possibilidade de escolha.

Finalmente, compartilhamos o ponto de vista de que, na investigação a respeito do tema das decisões econômicas, o enfoque deve recair, preferencialmente, sobre aqueles primeiros elementos, sejam eles chamados de "limitações estruturais", "determinantes sociais" ou outras expressões equivalentes em sentido. Mas entendemos, por outro lado, que uma compreensão mais clara acerca da questão em foco exige, em muitos casos, o exame do segundo lado dela, ou seja, o das "motivações", ou do "elemento psicológico".

Julgamos que, da compreensão sobre este ponto (ainda que menos precisa do que seria desejável), depende a possibilidade de obtenção de respostas a indagações como: por que se realizam inversões em dados períodos e em outros não? Por que se praticam certas categorias de inversões e não outras? Por que certos tipos de homens, mesmo detendo condições privilegiadas para realizar inversões, não as realizam, enquanto outros, aparentemente menos aquinhoados de tais condições, são os que as fazem? A compreensão dos resultados das atividades econômicas realizadas, em nossa opinião, somente pode ser alcançada, satisfatoriamente, se iluminadas por tais respostas.

O exame detido da discussão teórica acerca dos atos de escolha e das decisões delas decorrentes, em relação aos investimentos, é de relevante importância para os propósitos 
deste trabalho. Fornece alguma luz à análise empírica de um ponto aparentemente caótico se considerado na perspectiva, por exemplo, da teoria da conduta "ao acaso" ou outra do gênero.

De nossa parte, identificamo-nos com o ponto de vista dos autores que se posicionam pela existência de racionalidade no comportamento econômico dos indivíduos, porém, com uma ressalva, isto é: que esta racionalidade constitui-se em parte de uma racionalidade social mais ampla, que tem como base as relações sociais internas (estruturais) das diferentes sociedades - esta é a posição de Godelier (1983), por exemplo.

\section{REFERÊNCIAS BIBLIOGRÁFICAS}

AITKEN, Hugh. El enfoque empresarial en la historia de la economia. In: TAYLOR, G. R; ELLSWORTH, L. F. (Comp.). Historia Económica. Buenos Aires: Ediciones Economia y Empresa/ Prolam, p. 15-35, 1974.

BOUVIER, Jean. História Social e História Econômica. In: LABROUSSE, Ernest (Coord.). A História Social: problemas, fontes e métodos. Lisboa: Edições Cosmos, 1967, p. 279-292.

CHABERT, Alexandre. De quelques tendances récentes de I'histoire économique américaine: les "Business and Entrepreneurship Histories". Revue d'Histoire Economique et Sociale, XXXII, p. 187-199, 1954.

CHANDLER, Alfred. La historia de la administración empresarial como historia institucional. In: TAYLOR, G. R. et ELLSWORTH, L. F. (Comp.). Historia Económica. Buenos Aires: Ediciones Economia y Empresa/ Prolam, p. 15-35, 1974.

COLE, Arthur H. An approach to the study of Entrepreneurship: a tribute to Edwin F. Gay. The Journal of Economic History. Suplement VI, p. 1-15, 1946.

DAUMARD, Adeline. Hierarquia e riqueza na sociedade burguesa. São Paulo: Perspectiva, 1985.

FERNANDES, Florestan. A revolução burguesa no Brasil. Ensaio de interpretação sociológica. Rio de Janeiro: Guanabara, 1987.

FREITAS FILHO, Almir. História Econômica e História de Empresa: algumas reflexões metodológicas. Ensaios FEE, Porto Alegre, v. 10, n. 1, p. 168-177, 1989.

GODELIER, Maurice. Racionalidade e irracionalidade. Rio de Janeiro: Tempo Brasileiro, 1983.

MARTINS, José de Souza. Conde Matarazzo, o empresário e a empresa: estudo de sociologia do desenvolvimento. São Paulo: Hucitec, 1976.

O cativeiro da terra. São Paulo: Hucitec, 1986.

MARX, Karl. O capital. São Paulo: Nova Cultural, 1985, v. 1, t. 1-2. (Série: Os economistas)

SCHUMPETER, Joseph. Teoria do desenvolvimento econômico. (Uma investigação sobre lucros, capital, crédito, juro e ciclo econômico). São Paulo: Abril Cultural, 1982. (Série: Os economistas) 